\title{
超越传统光伏：弱光环境下可印刷介观钙铁矿太阳能 电池光电特性
}

\author{
李达 ${ }^{\dagger}$, 管炎俊 ${ }^{\dagger}$, 李代宇, 褚衍盟, 邹阳, 万宇坤, 梅安意, 荣耀光, 胡玥 ${ }^{*}$, 韩宏伟 ${ }^{*}$ \\ 华中科技大学武汉光电国家研究中心, 武汉 430074 \\ $\dagger$ 同等贡献 \\ *联系人, E-mail: yuehu@hust.edu.cn; hongwei.han@mail.hust.edu.cn
}

2020-06-24 收稿, 2020-07-30 修回, 2020-07-31 接受, 2020-08-03 网络版发表

国家自然科学基金(91733301，21702069)、中央大学基础研究基金、湖北省技术创新专项重大项目(2017AAA190)和国家大学生创新创业训练 计划(2020104870014)资助

\begin{abstract}
摘要 钙钛矿太阳能电池(perovskite solar cell, PSC)近年来发展十分迅速, 被认为是下一代光伏技术中最有前景的 候选者之一。其中，基于三层介孔膜结构的可印刷介观PSC以其廉价的原材料、简单的制备工艺以及良好的器件 稳定性获得了广泛关注. 本文测试了可印刷介观PSC小型模组 $(10 \mathrm{~cm} \times 10 \mathrm{~cm})$ 在不同光照强度条件下的光电性能, 并与商用的单晶硅(crystalline silicon, c-Si)、多晶硅(polycrystalline silicon, poly-Si)和碲化镉 $(\mathrm{CdTe})$ 太阳能电池进 行了对比. 结果表明, 随着光照强度的降低, c-Si、poly-Si、CdTe太阳能电池的光电转换效率(power conversion efficiency, PCE)均出现了不同程度的下降, 而可印刷介观PSC的PCE几乎呈线性增加. 当光照强度低于 0.3 个标准太 阳光 $\left(30 \mathrm{~mW} \mathrm{~cm}^{-2}\right)$ 时, 可印刷介观PSC已经开始展现出一定的光电转换效率优势; 当光照强度进一步降低至标准室 内弱光条件(1000 lux, 约 $0.3 \mathrm{~mW} \mathrm{~cm}^{-2}$ ) 时, 其PCE可达 $19.83 \%$, 高于其他商用太阳能电池. PSC在弱光环境下展现出 的优异性能为进一步扩展其在室内等场景的应用奠定了良好基础，这些潜在的新兴应用领域为PSC的商业化和大 规模生产提供了多种应用空间.
\end{abstract}

关键词钙钛矿太阳能电池, 弱光, 室内环境, 光电转换

能源为人类的生存和发展提供了重要物质基础. 工业革命推动着能源的改进和更替, 促进人类社会更 加文明和进步. 然而, 伴随着能源的巨大消耗, 以化石 能源为主导的能源体系面临着严峻挑战. 太阳能作为 一种重要的可再生清洁能源, 凭借储量丰富、绿色无 污染以及极小的地域影响等特点一直备受关注. 发展 大规模、可靠和成本效益高的光伏发电系统对于实现 国家能源结构优化的调整布局具有积极意义.

作为光伏发电的典型应用，太阳能电池是许多场 景下的理想电源, 但受制于强光发电等相关特性, 利用
太阳能电池发电的光伏产业目前主要应用于户外场景, 例如太阳能电站、城市照明、光伏建筑一体化(building integrated photovoltaic, BIPV)等. 然而, 室内场景下 的光伏发电技术尚不成熟, 应用产品并不广泛, 但却具 有极大的市场潜力, 尤其是小型消费电子产品(如计算 器、蓝牙键盘)、物联网设备(如自主传感器、无线节 点、工业4.0)、可穿戴应用设备(如智能手环、无线耳 机、手表) 等 ${ }^{[1 \sim 5]}$. 目前这些小型电子产品通常使用的是 纽扣电池或干电池作为电源, 但由于这些电池都含有 永、锰、镉、铅、锌等各种重金属元素，对环境的危

引用格式: 李达, 管炎俊, 李代宇, 等. 超越传统光伏: 弱光环境下可印刷介观钻钛矿太阳能电池光电特性. 科学通报, 2020, 65: 4272-4280 Li D, Guan Y J, Li D Y, et al. Beyond traditional photovoltaics: Photoelectric characteristics of printable mesoscopic perovskite solar cells under low light intensities (in Chinese). Chin Sci Bull, 2020, 65: 4272-4280, doi: 10.1360/TB-2020-0771 
害较大. 如果能利用室内弱光发电, 产生的电能用于对 这些小型电子产品供电, 将一定程度上减小对相关电 池的使用依赖，降低更换频率，从而减少污染，保护 环境.

自从19世纪法国科学家Becquerel发现光生伏打效 应(photovoltaic effect)以来, 太阳能光伏技术经历了长 期而曲折的发展 ${ }^{[6]}$. 一般来说, 根据其发展历程, 通常可 将太阳能电池划分为硅基太阳能电池、多元化合物薄 膜太阳能电池和新型太阳能电池. 其中, 硅基太阳能电 池主要包括单晶硅 (crystalline silicon, $\mathrm{c}-\mathrm{Si})^{[7,8]}$ 、多晶硅 (polycrystalline silicon, poly-Si) ${ }^{[9]}$ 、非晶硅(amorphous silicon, a-Si $)^{[7,8]}$ 三种. 晶硅太阳能电池也是发展历史最 为悠久、技术最为成熟一种，在当前光伏市场上占据 着主导地位. 多元化合物薄膜太阳能电池主要包括碲 化镉 $(\mathrm{CdTe})^{[10]}$ 、铜铟镓硒 $(\mathrm{Cu}-\mathrm{In}-\mathrm{Ga}-\mathrm{Se}, \mathrm{CIGS})^{[11]}$ 以及 $\mathrm{III} \sim \mathrm{V}$ 半导体 (如砷化镓, $\mathrm{GaAs})^{[12]}$ 太阳能电池, 这类电 池具有较低成本、柔韧易加工、可大面积生产等优点, 但由于制备过程仍然是能源密集型，制备成本难以进 一步降低. 此外, 环境污染问题和使用资源匮乏的稀有 元素也限制了这类电池的发展 ${ }^{[6]}$. 新型太阳能电池以染 料敏化太阳能电池 (dye-sensitized solar cell, DSSC) ${ }^{[13,14]}$ 、有机太阳能电池(organic photovoltaic, OPV) ${ }^{[15,16]}$ 和钙钛矿太阳能电池 (perovskite solar cell,

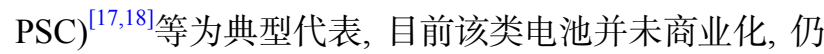
处于研发阶段 ${ }^{[6]}$. 与其他太阳能电池相比, DSSC太阳能 电池在室内人工光源下表现了出色性能 ${ }^{[19]}$, 因此被广 泛研究. DSSC在漫射光条件下也能保持高光电压 ${ }^{[20,21]}$, 在一些弱光条件下能获得超过 $20 \%$ 的光电转换效率 (photoelectric conversion efficiency, PCE) ${ }^{[14,22]}$, 还可以 做成柔性电池 ${ }^{[23]}$ 和光充电电池 ${ }^{[24]}$, 拓展了其在弱光条 件下的应用范围. 近年来, 基于可溶液制备、低成本和 高光电转换效率等优势, PSC得到了快速发展, 也引起 了研究人员的极大关注。在 1.0 个标准太阳光照射 $\left(100 \mathrm{~mW} \mathrm{~m}^{-2}\right)$ 下, 目前PSC的认证PCE已达到 $25.2 \%$, 超 过了 poly-Si太阳能电池和薄膜太阳能电池的最高PCE (数据来源: https://www.nrel.gov/pv/cell-efficiency.html). 除了在 1.0 个标准太阳光照射下表现出的高PCE外, PSC被发现在低强度光照下也展示出了优异的性 能 ${ }^{[2527]}$, 因此其在应用于传统光伏技术难以工作的室 内场景中具有巨大的潜力.

此前，我们已经报道过可印刷介观PSC小型模组 (基板面积 $10 \mathrm{~cm} \times 10 \mathrm{~cm}$ )在 1.0 个标准太阳光照射下的
PCE约为 $10 \%$, 同时在各种条件下具有极其优异的稳定

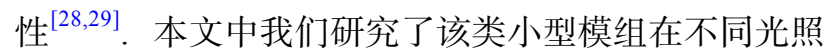
强度下的光电性能, 并与商用的c-Si、poly-Si和CdTe太 阳能电池进行了对比. 在测试过程中, 可印刷介观PSC 在弱光条件下展现出了一定的光电转换效率优势, 这 将为其在未来的多场景应用奠定良好的基础和广阔的 发展空间.

\section{1 实验}

本文涉及的4种太阳能电池小型模组中，可印刷介 观PSC小型模组为本课题组自行制备, 具体制备方法详 见文献 $[28,29]$. 其他 3 种太阳能电池(c-Si、poly-Si和 $\mathrm{CdTe}$ )为购买所得, 电池的具体尺寸、有效面积、制造 商等参数如表 $\mathrm{S} 1$ 所示. 本文模拟出的 $0.05 \sim 1.00 \mathrm{sun}$ 下的 光照强度利用Newport太阳模拟器(94063A型)获得, 标 准室内弱光 1000 lux下的光照强度利用Philips T5 $(6500 \mathrm{~K})$ 光源、PhilipT2 15WE27(2700 K)光源获得, 并 使用标准硅太阳能电池(Newport 91150V)、ENMARS TM-207型光功率计、TES-1334A型光照强度计进行校 准. 测试实验在温度为 $25^{\circ} \mathrm{C}$ 和湿度为 $30 \%$ 的空气环境 中进行. 通过Keithley 2400型数字源表测试了不同电 池在若干光照强度条件下的 $J-V$ 特性曲线，单片电池每 次直接测试时间约为 10 20 s. 暗电流测试使用电化学 阻抗谱(electrochemical impedance spectroscopy, EIS) (ZAHNER-PP211)测试完成.

\section{2 结果与讨论}

图1(a)展示了一个集成了不同光伏发电技术的房 屋示意图. 晴天时, 太阳光照强度可达0.8 1.0 个标准太 阳光(sun), 各类太阳能电池均能在此光照强度条件下 有效工作，在室内条件下，不同位置有不同的光照强 度，经实际测量，在阳光直射房间的阳光面为 $0.5 \sim 0.6$ sun, 在没有阳光直射的区域(即阴面)为 $0.1 \sim 0.2$ sun. 对 于背向阳光的房间，光照强度仅为 $0.05 \sim 0.08 \operatorname{sun}($ 光照 强度与光功率的关系见表 $\mathrm{S} 2$ ), 在这些光照强度较低的 区域, 传统的c-Si和poly-Si太阳能电池很难继续发电工 作. 图1(b)展示了4种太阳能电池小型模组的实物图, 包 括CdTe太阳能电池、c-Si太阳能电池、poly-Si太阳能 电池和可印刷介观PSC小型模组. 通常, 商用太阳能电 池可提供 $15 \%$ 20\%的光电转换效率, 但不用于零售. 这 些小型模组的PCE虽然较低于市场上主流光伏产品, 但 是当光照条件变化时, 电池性能的变化趋势是可以比 
(a)

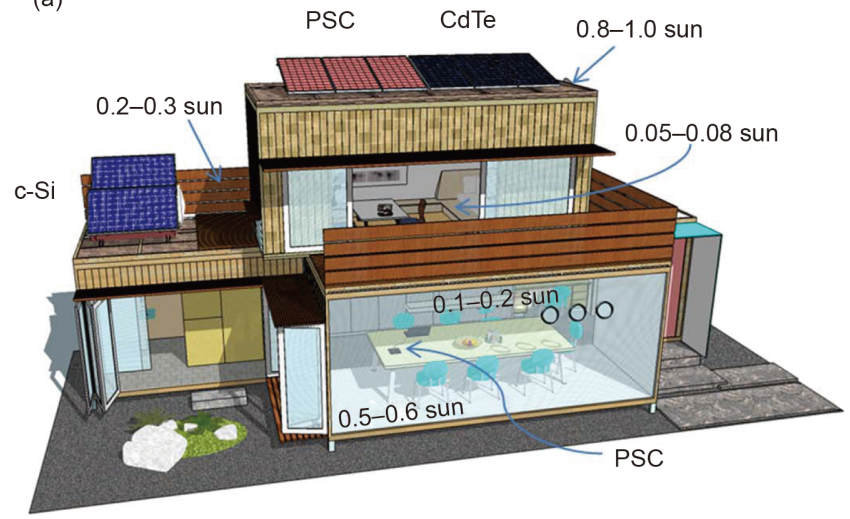

(b)

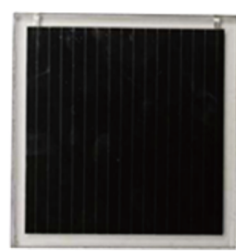

PSC

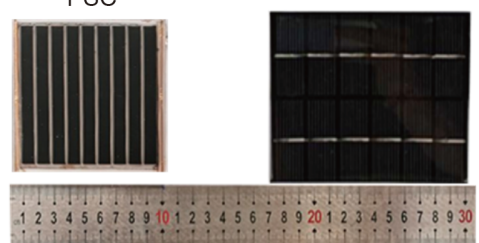

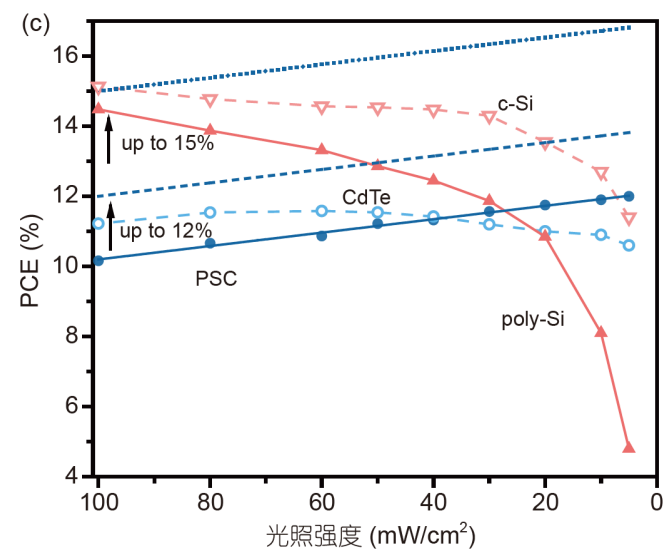

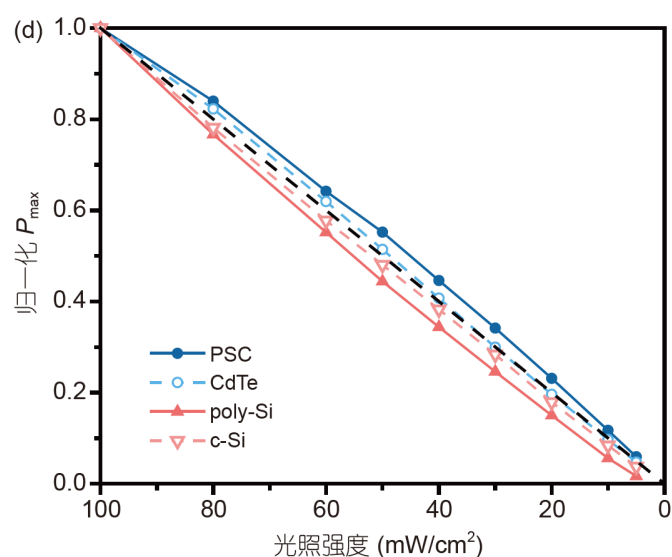

图 1 (网络版彩色)4种太阳能电池(PSC、CdTe、poly-Si、c-Si)在不同光照强度下的对比. (a) 晴天时房屋内外各区域的光照强度分布; (b) 实物 图对比; (c) 不同光照强度下PCE的变化趋势(虚线和点线分别指PSC小型模组PCE为 $12 \%$ 和 $15 \%$ 时预测的变化趋势); (d) 不同光照强度下归一化 $P_{\max }$ 的变化趋势

Figure 1 (Color online) The performance comparison of four small solar modules (PSC, CdTe, poly-Si, c-Si) under different light intensities. (a) Light intensity distribution in various areas inside and outside the house on a sunny day; (b) digital images of four small solar modules; (c) the PCE under different light intensities (dashed line and dotted line refer to predicted PCE trend of PSC mini-modules of 12\% and 15\%, respectively); (d) the normalized $P_{\max }$ under different light intensities

\section{较的, 其结果仍具有一定的参考价值.}

我们对 4 种太阳能电池在不同光照强度下的性能 进行了测试，其PCE的变化如图1(c)所示，其他性能参 数 $V_{\mathrm{OC}} 、 J_{\mathrm{SC}} 、 \mathrm{FF}$ 和 $P_{\max }$ 的变化如图 $\mathrm{S} 1$ 所示. 可以看出, 当光照强度从 100 降低到 $5 \mathrm{~mW} \mathrm{~cm}$ 时, 可印刷介观 PSC的PCE随着光照强度的降低而上升, 主要是 $F F$ 的提 高. 单晶硅、多晶硅和碲化镉太阳能电池的PCE以不同 的速率下降, 尤其是多晶硅的PCE呈指数下降. 具体性 能数据如图S2和表S3 S6所示. 结合表 1进一步分析发 现, 当光照强度小于 0.3 sun时, 可印刷介观 PSC的PCE 高于poly-Si和CdTe太阳能电池, 开始展现出一定的光 电转换效率优势. 在极低的 0.05 sun光照强度下, 可印 刷介观PSC的PCE高于其他所有的太阳能电池. 随着䥻 铁矿光伏技术的日益进步, PSC的最高PCE公证记录不
断被刷新. 可以预见, 可印刷介观PSC的PCE也将不断 攀升. 图1(c)预测了提升至不同PCE的情况分析，其中 虚线和点线分别表示PCE达到 $12 \%$ 和 $15 \%$ 的情况. 根据 这一线性趋势，如果可印刷介观PSC小型模组在 1.0 个 标准太阳光照射下的PCE达到 $12 \%$, 那么在光照强度小 于0.5 sun的情况下，其PCE便将超过c-Si、poly-Si和 CdTe太阳能电池; 如果其在 1.0 个标准太阳光照射下的 PCE能进一步达到 $15 \%$, 那么其 $\mathrm{PCE}$ 在大多数光照强度 条件下都将超过c-Si、poly-Si和CdTe太阳能电池, 这也 展示出了可印刷介观PSC在未来的多应用场景中的无 限可能.

在实际应用中，常常需要考虑太阳能电池的实际 输出功率. 图1(d) 比较了随着光照强度的降低, 4 种太 阳能电池的功率输出情况. 为了揭示不同太阳能电池 
表 1 4种太阳能电池(PSC、CdTe、poly-Si、c-Si)在不同光照强度条件下的光电参数

Table 1 Photovoltaic parameters of four small solar modules (PSC, CdTe, poly-Si, c-Si) under different light intensities

\begin{tabular}{|c|c|c|c|c|c|c|c|}
\hline 光照强度 & 电池 & $V_{\mathrm{OC}}(\mathrm{V})$ & $J_{\mathrm{SC}}\left(\mathrm{mA} / \mathrm{cm}^{2}\right)$ & $\mathrm{FF}$ & $P_{\max }\left(\mathrm{mW} / \mathrm{cm}^{2}\right)$ & $P_{\text {in }}\left(\mathrm{mW} / \mathrm{cm}^{2}\right)$ & PCE $(\%)$ \\
\hline \multirow[t]{4}{*}{1.0 sun } & PSC & 8.224 & 2.48 & 0.498 & 10.16 & 100 & 10.16 \\
\hline & $\mathrm{CdTe}$ & 12.535 & 1.52 & 0.591 & 11.22 & 100 & 11.22 \\
\hline & Poly-Si & 7.240 & 2.87 & 0.696 & 14.48 & 100 & 14.48 \\
\hline & $\mathrm{c}-\mathrm{Si}$ & 7.363 & 2.67 & 0.770 & 15.13 & 100 & 15.13 \\
\hline \multirow[t]{4}{*}{0.3 sun } & PSC & 7.626 & 0.76 & 0.602 & 3.47 & 30 & 11.57 \\
\hline & $\mathrm{CdTe}$ & 11.311 & 0.46 & 0.646 & 3.36 & 30 & 11.20 \\
\hline & Poly-Si & 6.503 & 0.87 & 0.628 & 3.56 & 30 & 11.87 \\
\hline & $\mathrm{c}-\mathrm{Si}$ & 6.800 & 0.80 & 0.786 & 4.29 & 30 & 14.30 \\
\hline \multirow[t]{4}{*}{0.05 sun } & PSC & 7.083 & 0.13 & 0.653 & 0.60 & 5 & 12.00 \\
\hline & $\mathrm{CdTe}$ & 10.021 & 0.08 & 0.663 & 0.53 & 5 & 10.60 \\
\hline & Poly-Si & 5.072 & 0.15 & 0.329 & 0.24 & 5 & 4.80 \\
\hline & c-Si & 6.053 & 0.13 & 0.702 & 0.57 & 5 & 11.40 \\
\hline
\end{tabular}

的 $P_{\text {max }}$ 随光照强度的变化趋势, 我们对在标准太阳光照 下的光功率进行了归一化处理. 理想状态下, 如果太阳 能电池的PCE与光照强度无关, 那么电池的输出功率将 随着光照强度的降低而线性降低, 即图1(d)中的虚线所 示. 根据之前的数据结果分析, 由于 $\mathrm{c}-\mathrm{Si}$ 和poly-Si太阳 能电池的PCE随着光照强度的降低而降低, 因此理论上 输出功率下降的速度比理想状态更快. 相反, 随着光照 强度的降低，由于可印刷介观PSC具有更好的弱光性 能，输出功率下降的速度比理想状态更慢. CdTe太阳 能电池输出功率的下降趋势接近于线性.

把电池在两个不同光照强度下的光功率相除，得 到一个百分数, 这个百分数被称为比率. 通过比较比率 的大小, 可以直观地判断电池的弱光性能. 例如, 在图 2 (a)中, 我们展示了 0.1 sun时的 $P_{\text {max }}$ 与 1 sun时的 $P_{\text {max }}$ 之比 $\left(P_{\text {max }, 0.1 \text { sun }} / P_{\text {max }, 1 \text { sun }}\right)$ 和0.05 sun时的 $P_{\text {max }}$ 与 $1 \operatorname{sun}$ 时的 $P_{\text {max }}$ 之比 $\left(P_{\max , 0.05 \operatorname{sun}} / P_{\max , 1 \text { sun }}\right)$. 如果 $P_{\max }$ 随着光照强度线性下 降, 则这两个比率应该分别为 $10 \%$ 和 $5 \%$. 根据实际实验 数据测得, 对于 $\left(P_{\max , 0.1 \text { sun }} / P_{\max , 1 \text { sun }}\right)$ 这个分析点, PSC、 CdTe、poly-Si和c-Si太阳能电池的比率分别为 $11.7 \%$ 、 $9.7 \% 、 5.6 \%$ 和 $8.4 \%$; 而对于 $\left(P_{\max , 0.05 \text { sun }} / P_{\max , 1 \text { sun }}\right)$ 这个分 析点, PSC、CdTe、poly-Si和c-Si太阳能电池的比率分 别为 $5.9 \% 、 4.7 \% 、 1.7 \% 、 3.8 \%$. PSC在所有太阳能电 池中比率最高，表明可印刷介观PSC相比于其他商用 太阳能电池具有一定的弱光性能优势.

为了分析低光照强度条件下不同电池性能的变化, 采用一个简单的等效电路模型来仿真模拟，如图S3所
示 $^{[30]}$. $J$ 为净输出电流密度, $J_{\mathrm{d}}$ 为二极管电流密度, $J_{\mathrm{ph}}$ 为光生电流密度, $J_{\mathrm{sh}}$ 为流过并联电阻 $\left(R_{\mathrm{sh}}\right)$ 的漏电流密 度, $R_{\mathrm{S}}$ 为串联电阻. 其中, $J$ 和 $J_{\mathrm{ph}}$ 都是电压 $V$ 和人射光光 照强度 $I$ 的函数. 根据欧姆定律, 漏电流密度 $J_{\mathrm{sh}}$ 可以用式 (1)表示:

$J_{\mathrm{sh}}=\frac{V-J R_{\mathrm{s}}}{R_{\mathrm{sh}}}$.

根据等效电路分析，并联电阻 $R_{\mathrm{sh}}$ 可以通过计算暗 电流在 $J\left(0 \mathrm{~mW} / \mathrm{cm}^{2}, 0 \mathrm{~V}\right)$ 处的斜率负倒数得到 ${ }^{[30]}$. 我们 对4种太阳能电池的暗电流进行了表征测试，而暗电流 大小与漏电流 $J_{\mathrm{sh}}$ 有关，其结果如图2(b)所示. 根据测试 结果, 漏电流 $J_{\mathrm{sh}}$ 的大小顺序为 $\mathrm{PSC}<\mathrm{CdTe}<\mathrm{c}-\mathrm{Si}<$ poly-Si. 根据暗电流的一阶导数计算了 4 种太阳能电池的并联 电阻 $R_{\mathrm{sh}}$, 分别为 $7.54 \times 10^{8} 、 5.90 \times 10^{8} 、 7.84 \times 10^{7}$ 、 $4.95 \times 10^{5} \Omega \mathrm{cm}^{2}$ ，大小关系与 $J_{\mathrm{sh}}$ 相反. 结合等效电路分 析得出, 当人射光的光照强度较低时, 光生电流减少, 串联电阻造成的损耗越来越小，但是漏电流所占比例 增加，分流电阻造成的损耗增加，导致损耗总体上增 加, 因此性能变差 ${ }^{[31,32]}$. 在4种太阳能电池中, 可印刷介 观PSC的并联电阻最大, 漏电流最小, 因此随着光照强 度降低，分流电阻造成的损耗小于串联电阻减少的损 耗，解释了为什么可印刷介观PSC的FF随着光照强度 减少而增加. 这可能是其在弱光条件下具有一定光电 转换效率优势的原因之一. 此外, 我们发现FF随光照强 度的变化趋势与 $\mathrm{PCE}$ 相似, 意味着 $\mathrm{FF}$ 是影响 $\mathrm{PCE}$ 的主要 因素。 

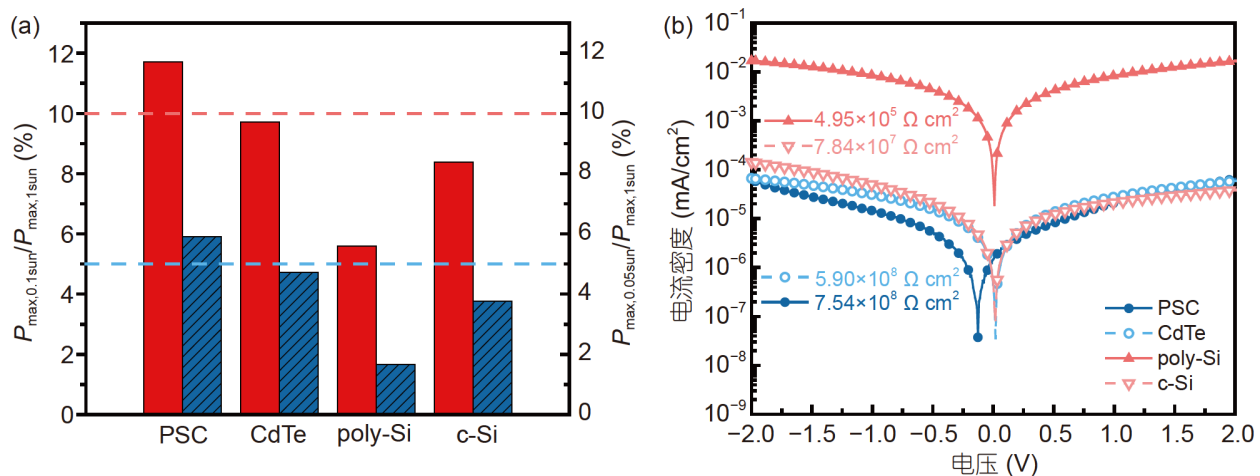

图 2 (网络版彩色)4种太阳能电池(PSC、CdTe、poly-Si、c-Si)在弱光下的性能对比. (a) $P_{\max , 0.1 \text { s sun }} / P_{\max , 1 \text { sun }}$ 和 $P_{\text {max }, 0.05 \text { sun }} / P_{\max , 1 \text { sun }}$; (b) 暗态 $J-V$ 曲线 特性(图中数据是从不同电池暗电流中提取的并联电阻)

Figure 2 (Color online) The performance comparison of four small solar modules (PSC, CdTe, poly-Si, c-Si) under low-intensity illumination. (a) $P_{\max , 0.1 \text { surn }} / P_{\max , 1 \text { sun }}$ and $P_{\max , 0.05 \mathrm{sun} /} / P_{\max , 1 \text { sun }}$ (b) dark $J-V$ characteristics (the data in the figure is the shunt resistance extracted from the dark current)

我们进一步测试了 4 种太阳能电池在标准室内照 度为 1000 lux、色温为 6500 和 $2700 \mathrm{~K}$ 时的 $J-V$ 曲线，如 图3所示, 相应的光伏参数见表 2 . 标准室内照度区域已 由光照强度计校准, 如图S4所示. 在这种低强度光照下, poly-Si太阳能电池几乎不能工作, $\mathrm{c}-\mathrm{Si}$ 太阳能电池的 PCE下降到 $6 \%$ 7\%. 相反, CdTe和PSC太阳能电池仍能 有效工作. 值得注意的是, 可印刷介观PSC在1000 lux弱 光条件下的PCE明显提升，其在 $6500 \mathrm{~K}$ 的色温条件下 PCE为 $17.61 \%$, 在 $2700 \mathrm{~K}$ 的色温条件下, PCE可达 $19.83 \%$. 这也进一步印证了可印刷介观PSC在弱光条 件下具有一定的优势.

可印刷介观PSC小型模组在不同光照强度下的优 异性能为其在各种场景中的应用提供了可能性，如图4 所示. 在传统的应用领域中, PSC发挥着越来越重要的 作用，并在许多方面显示出了良好的应用前景. 例如，
2018年, 万度光能(Wondersolar)公司展示了一座 $110 \mathrm{~m}^{2}$ 的可印刷介观PSC电站 ${ }^{[33]}$; 瑞士的Solaronix公司证明了 将染料敏化电池(未来可能是PSC) 与建筑物集成以制 造BIPV幕墙的可能性(信息来源：http://www.solaronix. $\mathrm{com} /$ solarcells). 对于新兴的应用领域, 由于PSC可以在 轻质柔性基底上制造，弯曲的形状使其易于在户外移 动和工作 ${ }^{[34]}$. 在室内, 由于出色的弱光性能, $\mathrm{PSC}$ 可以 为手机等电器进行充电(信息来源: https://www.ncu. edu.tw/en/campus/article/1782), 这也大大拓宽了PSC的 应用范围. 在更高端的航天领域中，在距地面 $35 \mathrm{~km}$ 的 相邻空间的极端环境下，PSC在AM 1.5辐射下获得了 $95 \%$ 以上的初始 $\mathrm{PCE}^{[35]}$.

不可否认，PSC目前距离商业化还有一段距离，但 是前景却充满希望和光明. 对于传统领域, PSC仍然需 要科研工作者以及企业研发人员夜以继日的努力和奋
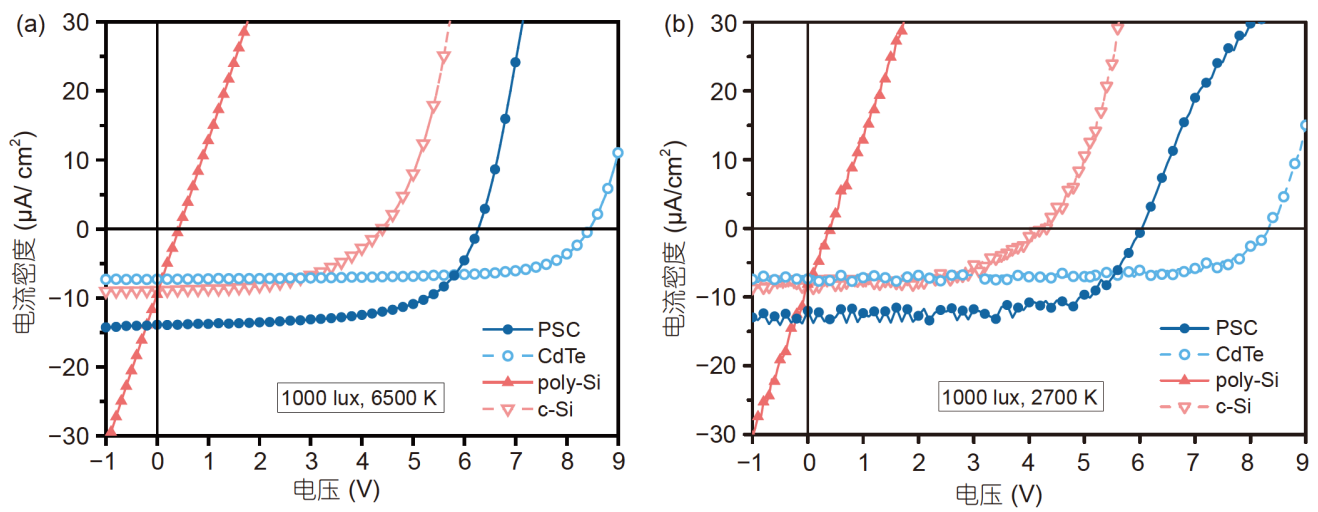

图 3 (网络版彩色)4种太阳能电池(PSC、CdTe、poly-Si、c-Si)在1000 lux、不同色温条件下的 $J-V$ 曲线. (a) $6500 \mathrm{~K}$; (b) $2700 \mathrm{~K}$

Figure 3 (Color online) $J-V$ curves of four small solar modules (PSC, CdTe, poly-Si, c-Si) at 1000 lux and different color temperatures. (a) $6500 \mathrm{~K}$; (b) $2700 \mathrm{~K}$ 
表 2 4种太阳能电池(PSC、CdTe、poly-Si、c-Si)在标准室内照度1000 lux(色温: 6500, $2700 \mathrm{~K}$ )条件下的性能表现

Table 2 Performance of four small solar modules (PSC, CdTe, poly-Si, c-Si) under standard indoor light conditions of 1000 lux (color temperature: $6500,2700 \mathrm{~K})$

\begin{tabular}{|c|c|c|c|c|c|c|c|c|}
\hline 电池 & 光源 & 色温(K) & $P_{\text {in }}\left(\mu \mathrm{W} / \mathrm{cm}^{2}\right)$ & $V_{\mathrm{OC}}(\mathrm{V})$ & $J_{\mathrm{SC}}\left(\mu \mathrm{A} / \mathrm{cm}^{2}\right)$ & $\mathrm{FF}(\%)$ & $P_{\max }\left(\mu \mathrm{W} / \mathrm{cm}^{2}\right)$ & PCE $(\%)$ \\
\hline $\mathrm{c}-\mathrm{Si}$ & \multirow{4}{*}{ PhilipT5 } & \multirow{4}{*}{6500} & \multirow{4}{*}{310} & 4.3995 & 8.9 & 51.49 & 20.2 & 6.51 \\
\hline poly-Si & & & & 0.3998 & 9.5 & 26.28 & 1.0 & 0.32 \\
\hline $\mathrm{CdTe}$ & & & & 8.4496 & 7.3 & 69.27 & 42.7 & 13.77 \\
\hline $\mathrm{PSC}$ & & & & 6.2485 & 13.9 & 62.84 & 54.6 & 17.61 \\
\hline $\mathrm{c}-\mathrm{Si}$ & \multirow{4}{*}{$\begin{array}{l}\text { PhilipT2 } \\
\text { 15WE27 }\end{array}$} & \multirow{4}{*}{2700} & \multirow{4}{*}{275.4} & 4.3143 & 7.5 & 59.54 & 19.4 & 7.04 \\
\hline poly-Si & & & & 0.3994 & 8.1 & 29.56 & 1.0 & 0.36 \\
\hline $\mathrm{CdTe}$ & & & & 8.2972 & 7.4 & 73.58 & 45.0 & 16.34 \\
\hline PSC & & & & 6.0022 & 12.0 & 75.82 & 54.6 & 19.83 \\
\hline
\end{tabular}

斗, 以达到与其他光伏技术相当的水平. 对于新兴领域, PSC除了在航天领域的应用外, 在室内的应用前景非常 设一个小型模块在 1.0 个标准太阳光照射下可以达到 广阔．例如，发光二极管和苂光灯的照明波长都在 350 750 nm之间, 其光照强度在100 1000 lux之间. 假 $15 \%$ 的PCE, 则在 $200 \operatorname{lux}($ 约 $77 \mu \mathrm{W} \mathrm{cm}$ ) 时, PCE将从图 1(c)中的线性函数增加到约 $17 \%$. 这意味着 $15 \mathrm{~mW}$ 的功 率输出只需要约 $0.1 \mathrm{~m}^{2}$, 其大小可以完全存放于一个背

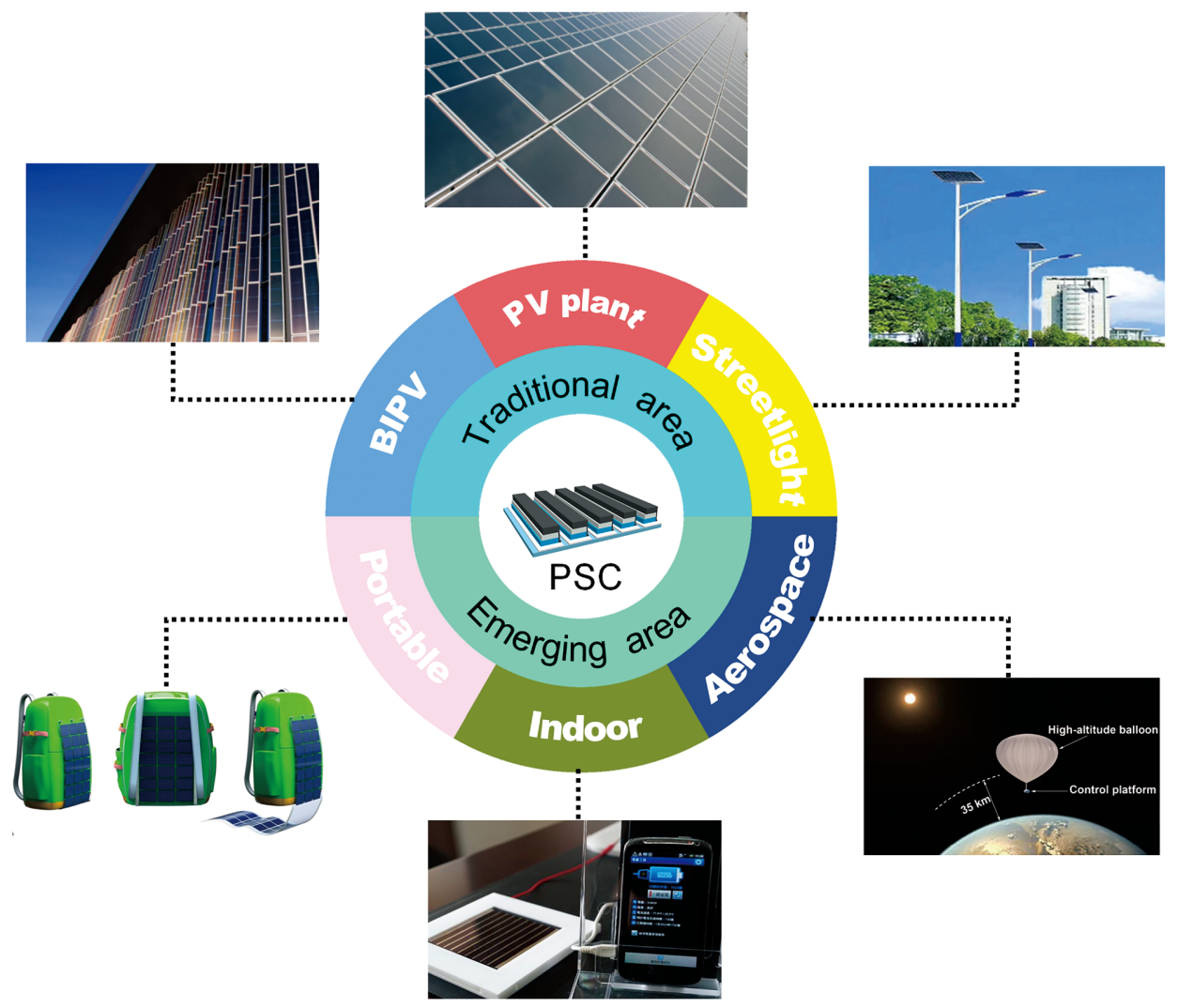

图 4 (网络版彩色)钻针矿太阳能电池在传统和新兴领域的应用. 例如, BIPV(图片来源: http://www.solaronix.com/solarcells)、光伏电站 ${ }^{[33]}$ 、路 灯(图片来源: http://www.whlrgd.com/portal/list/index/id/8.html)、便携式设备 ${ }^{[34]}$ 、室内设备(图片来源: https://www.ncu.edu.tw/en/campus/article/ 1782)和航空航天应用 ${ }^{[35]}$

Figure 4 (Color online) The traditional and emerging areas for the applications of PSCs, from BIPV (picture source: http://www.solaronix.com/ solarcells), PV plant ${ }^{[33]}$ and streetlight (picture source: http://www.whlrgd.com/portal/list/index/id/8.html) to portable devices ${ }^{[34]}$, indoor devices (picture source: https://www.ncu.edu.tw/en/campus/article/1782) and aerospace applications ${ }^{[35]}$ 
包中, 表明PSC不仅可以为一些物联网和无线传感器设 备供电, 还可以凭借其材料的柔性特质, 做到便携出行, 这也为其日后的多场景发展奠定了良好的基础.

\section{3 结论}

综上所述, 我们研究了可印刷介观PSC小型模组在 不同强度光照条件下的性能表现. 通过与目前已商业 化的单晶硅、多晶硅、碲化镉薄膜太阳能电池在不同 光照强度条件下进行对比测试, 发现可印刷介观PSC表 现出良好的弱光性能. 当光照强度小于 0.3 个标准太阳
光 $\left(30 \mathrm{~mW} \mathrm{~cm}^{-2}\right)$ 时, 可印刷介观PSC开始展现出一定的 光电转换效率优势. 目前, 通过相关技术工艺的改善与 优化, 可印刷介观PSC小型模组的实验室PCE已经达到 $14 \%$. 如果PCE能够进一步提高至 $15 \%$ ，那么在低光照 强度下PSC在室内应用中相比于传统光伏技术将具有 显著的优势，在应用于消费电子产品、物联网、可穿 戴应用设备等场景方面也将更具潜力. 无论是传统的 应用领域，还是潜在的新兴应用领域，我们相信PSC在 未来的商业化和大规模生产中一定会凭借自身优势具 有广阔的发展前景.

\section{致谢感谢华中科技大学分析测试中心对本论文的支持和帮助.}

\section{参考文献}

1 Jean J, Brown P R, Jaffe R L, et al. Pathways for solar photovoltaics. Energy Environ Sci, 2015, 8: 1200-1219

2 Ostfeld A E, Arias A C. Flexible photovoltaic power systems: Integration opportunities, challenges and advances. Flex Print Electron, 2017, 2: 013001

3 Bouguera T, Diouris J F, Chaillout J J, et al. Energy consumption model for sensor nodes based on LoRa and LoRaWAN. Sensors, 2018, 18: 2104

4 Reese M O, Glynn S, Kempe M D, et al. Increasing markets and decreasing package weight for high-specific-power photovoltaics. Nat Energy, 2018, 3: 1002-1012

5 Correa-Baena J P, Saliba M, Buonassisi T, et al. Promises and challenges of perovskite solar cells. Science, 2017, 358: 739-744

6 Palz W. Power for the World: The Emergence of Electricity from the Sun. Singapore: Pan Stanford Publishing Press, 2010

7 Randall J F, Jacot J. Is AM1.5 applicable in practice? Modelling eight photovoltaic materials with respect to light intensity and two spectra. Renew Energy, 2003, 28: 1851-1864

8 Randall J. Designing Indoor Solar Products: Photovoltaic Technologies for AES. West Sussex: John Wiley \& Sons Press, 2006

9 Zettl M, Stern O, Mayer O, et al. Indoor characterization of photovoltaic modules under various conditions. In: Tsai B K, ed. Proceedings of the Society of Photo-optical Instrumentation Engineers (SPIE). 2008, 7046: 70460M

10 Freunek M, Freunek M, Reindl L M. Maximum efficiencies of indoor photovoltaic devices. IEEE J Photovoltaics, 2013, 3: 59-64

11 Sacco A, Rolle L, Scaltrito L, et al. Characterization of photovoltaic modules for low-power indoor application. Appl Energy, 2013, 102: 12951302

12 Mathews I, Kelly G, King P J, et al. GaAs solar cells for Indoor Light Harvesting. In: Proceedings of the 2014 IEEE 40th Photovoltaic Specialist Conference (PVSC). Denver: IEEE Press, 2014. 510-513

13 Müller M F. Indoor photovoltaics: Efficiencies, measurements and design. In: Tiwari A, Boukherroub R, Sharon M, eds. Solar Cell Nanotechnology. Salem: Scrivener Publishing LLC Press, 2013. 203-222

14 Freitag M, Teuscher J, Saygili Y, et al. Dye-sensitized solar cells for efficient power generation under ambient lighting. Nat Photon, 2017, 11: 372378

15 Steim R, Ameri T, Schilinsky P, et al. Organic photovoltaics for low light applications. Sol Energy Mater Sol Cells, 2011, 95: 3256-3261

16 Hou J, Inganäs O, Friend R H, et al. Organic solar cells based on non-fullerene acceptors. Nat Mater, 2018, 17: 119-128

17 Kojima A, Teshima K, Shirai Y, et al. Organometal halide perovskites as visible-light sensitizers for photovoltaic cells. J Am Chem Soc, 2009, 131: $6050-6051$

18 Kim H S, Lee C R, Im J H, et al. Lead iodide perovskite sensitized all-solid-state submicron thin film mesoscopic solar cell with efficiency exceeding 9\%. Sci Rep, 2012, 2: 591

19 Kalyanasundaram K. Dye-sensitized Solar Cells. New York: EPFL Press, 2010

20 Gurung A, Qiao Q. Solar charging batteries: Advances, challenges, and opportunities. Joule, 2018, 2: 1217-1230

21 Yu M, McCulloch W D, Huang Z, et al. Solar-powered electrochemical energy storage: An alternative to solar fuels. J Mater Chem A, 2016, 4: 2766-2782

22 Tingare Y S, Vinh N S, Chou H H, et al. New acetylene-bridged 9,10-conjugated anthracene sensitizers: Application in outdoor and indoor dye- 
sensitized solar cells. Adv Energy Mater, 2017, 7: 1700032

23 De Rossi F, Pontecorvo T, Brown T M. Characterization of photovoltaic devices for indoor light harvesting and customization of flexible dye solar cells to deliver superior efficiency under artificial lighting. Appl Energy, 2015, 156: 413-422

24 Kim B M, Lee M H, Dilimon V S, et al. Indoor-light-energy-harvesting dye-sensitized photo-rechargeable battery. Energy Environ Sci, 2020, 13: $1473-1480$

25 Lee H K H, Barbé J, Meroni S M P, et al. Outstanding indoor performance of perovskite photovoltaic cells-Effect of device architectures and interlayers. Sol RRL, 2019, 3: 1800207

26 Chen C Y, Chang J H, Chiang K M, et al. Perovskite photovoltaics for dim-light applications. Adv Funct Mater, 2015, 25: 7064-7070

27 Juang S S Y, Lin P Y, Lin Y C, et al. Energy harvesting under dim-light condition with dye-sensitized and perovskite solar cells. Front Chem, 2019, 7: 00209

$28 \mathrm{Fu} \mathrm{Z,} \mathrm{Xu} \mathrm{M,} \mathrm{Sheng} \mathrm{Y,} \mathrm{et} \mathrm{al.} \mathrm{Encapsulation} \mathrm{of} \mathrm{printable} \mathrm{mesoscopic} \mathrm{perovskite} \mathrm{solar} \mathrm{cells} \mathrm{enables} \mathrm{high} \mathrm{temperature} \mathrm{and} \mathrm{long-term} \mathrm{outdoor} \mathrm{stability.}$ Adv Funct Mater, 2019, 29: 1809129

$29 \mathrm{Hu} \mathrm{Y}$, Si S, Mei A, et al. Stable large-area $\left(10 \times 10 \mathrm{~cm}^{2}\right)$ printable mesoscopic perovskite module exceeding $10 \%$ efficiency. Sol RRL, 2017, 1: 1600019

30 Proctor C M, Nguyen T Q. Effect of leakage current and shunt resistance on the light intensity dependence of organic solar cells. Appl Phys Lett, 2015, 106: 083301

31 Lechêne B P, Cowell M, Pierre A, et al. Organic solar cells and fully printed super-capacitors optimized for indoor light energy harvesting. Nano Energy, 2016, 26: 631-640

32 Di Giacomo F, Zardetto V, Lucarelli G, et al. Mesoporous perovskite solar cells and the role of nanoscale compact layers for remarkable all-round high efficiency under both indoor and outdoor illumination. Nano Energy, 2016, 30: 460-469

33 Rong Y, Hu Y, Mei A, et al. Challenges for commercializing perovskite solar cells. Science, 2018, 361: eaat8235

34 Wang Z, Song Z, Yan Y, et al. Perovskite-A perfect top cell for tandem devices to break the S-Q limit. Adv Sci, 2019, 6: 1801704

35 Tu Y G, Xu G N, Yang X Y, et al. Mixed-cation perovskite solar cells in space. Sci China-Phys Mech Astron, 2019, 62: 974221

\section{补充材料}

表S1 四种太阳能电池(PSC、CdTe、poly-Si、c-Si)的产品参数

表S2 光照强度和光功率的关系(0.1 1.0 sun)

表S3 可印刷介观钲钛矿太阳能电池(PSC)在不同光强条件下的光电参数

表S4 多晶硅太阳能电池(poly-Si)在不同光强条件下的光电参数

表S5 碲化镉太阳能电池 $(\mathrm{CdTe})$ 在不同光强条件下的光电参数

表S6 单晶硅太阳能电池 (c-Si) 在不同光强条件下的光电参数

图S1 四种太阳能电池(PSC、CdTe、poly-Si、c-Si)在不同光强条件下的光电参数

图S2 四种太阳能电池(PSC、CdTe、poly-Si、c-Si) 在不同光强条件下的 $J-V$ 曲线

图S3 典型太阳能电池电流路径和电阻的简单电路模型

图S4 自建室内照明区 $(23.5 \mathrm{~cm} \times 23.0 \mathrm{~cm})$ 照度分布图

本文以上补充材料见网络版csb.scichina.com. 补充材料为作者提供的原始数据, 作者对其学术质量和内容负责. 


\title{
Beyond traditional photovoltaics: Photoelectric characteristics of printable mesoscopic perovskite solar cells under low light intensities
}

\author{
$\mathrm{Da} \mathrm{Li}^{\dagger}$, Yanjun Guan ${ }^{\dagger}$, Daiyu Li, Yanmeng Chu, Yang Zou, Yukun Wan, Anyi Mei, Yaoguang Rong, \\ Yue $\mathrm{Hu}^{*} \&$ Hongwei Han \\ Wuhan National Laboratory for Optoelectronics, Huazhong University of Science and Technology, Wuhan 430074, China \\ $\uparrow$ Equally contributed to this work \\ * Corresponding authors, E-mail: yuehu@hust.edu.cn; hongwei.han@mail.hust.edu.cn
}

Perovskite solar cells (PSCs) are considered as one of the most promising candidates for next-generation photovoltaic technology due to their rapid development in recent years. Among them, the printable mesoscopic PSC based on the triple mesoporous layers has attracted wide attention for the advantages of low-cost raw materials, simple manufacturing process and excellent long-term stability. At present, the studies are focused on the applications of PSCs under one standard sunlight (1.0 sun, $100 \mathrm{~mW} \mathrm{~cm}$ ), while neglecting the applications under low light intensities. In this work, we demonstrate that PSCs have outstanding performance under low-intensity illumination, and can be applied for indoor applications, for which traditional PV technologies can hardly compete with.

Previously, we have reported printable mesoscopic PSC mini-modules (substrate area $10 \mathrm{~cm} \times 10 \mathrm{~cm}$ ) with an efficiency of $\sim 10 \%$ under one sun illumination and outstanding stability under various conditions. Herein, we investigated the performance of four small modules under the illumination of different light intensities (1.0-0.05 sun), including PSC, monocrystalline silicon (c-Si), polycrystalline silicon (poly-Si) and cadmium telluride $(\mathrm{CdTe})$ solar cells. When the light intensity decreased from 1.0 to 0.05 sun, we observed a drop of photoelectric conversion efficiency (PCE) of c-Si, poly-Si and CdTe solar cells at various rates. On the contrary, we found that the PCE of PSC mini-modules increased linearly when light intensity decreased. The PCE of the PSC mini-modules was higher than that of poly-Si and CdTe solar cells when the light intensity was under 0.3 sun. Under a very low light intensity of 0.05 sun, the PCE of PSC module was higher than that of all other solar cells. It can be foreseen in the near future that the PCE of PSC modules will reach a much higher value. According to this linear upward trend, if the efficiency of PSC mini-modules reaches $12 \%$ at 1.0 sun, it will completely surpass the PCE of c-Si, poly-Si and CdTe solar cells under the light intensity less than 0.5 sun. Furthermore, if the efficiency of PSC mini-modules reaches $15 \%$ at 1.0 sun, it will completely surpass the PCE of c-Si, poly-Si and CdTe solar cells under most intensity illuminations, showing huge potential in various application scenarios.

For practical applications, the output power density $\left(P_{\max }\right)$ of different solar cells should be taken into account. We introduced ratios of the $P_{\max }$ at 0.1 sun to the $P_{\max }$ at 1 sun $\left(P_{\max , 0.1 \text { sun }} / P_{\max , 1 \text { sun }}\right)$ and the $P_{\max }$ at 0.05 sun to the $P_{\max }$ at 1 sun $\left(P_{\max , 0.05 \mathrm{sun}} / P_{\max , 1 \text { sun }}\right)$ to compare the changes in performance from 1.0 to 0.1 and 0.05 sun for all these solar cells. The PSC showed the highest ratio among all the solar cells. According to the equivalent circuit model of solar cells, the dark current of different devices were characterized which is related to the leakage current $\left(J_{\mathrm{sh}}\right)$ in the device. In general, the magnitude of the leakage current has the order: $\mathrm{PSC}<\mathrm{CdTe}<\mathrm{c}-\mathrm{Si}<$ poly-Si. The shunt resistances $\left(R_{\mathrm{sh}}\right)$ of four types of solar cells were calculated as $7.5 \times 10^{8}, 5.90 \times 10^{8}, 7.84 \times 10^{7}, 4.95 \times 10^{5} \Omega \mathrm{cm}^{2}$, which have the reverse order of $J_{\text {sh }}$. For cells with high $J_{\mathrm{sh}}$, the PSC mini-modules had less loss caused by the $R_{\mathrm{sh}}$. This result explained why the FF of PSC mini-modules increased when the light intensity decreased. When the light intensity was further reduced to the standard indoor low light conditions (1000 lux, about $0.3 \mathrm{~mW} \mathrm{~cm}^{-2}$ ), printable mesoscopic PSC had the highest PCE of $19.83 \%$ and $17.61 \%$ at two different color temperatures of 6500 and $2700 \mathrm{~K}$, respectively.

perovskite solar cell, low light, indoor environment, photoelectric conversion

doi: 10.1360/TB-2020-0771 